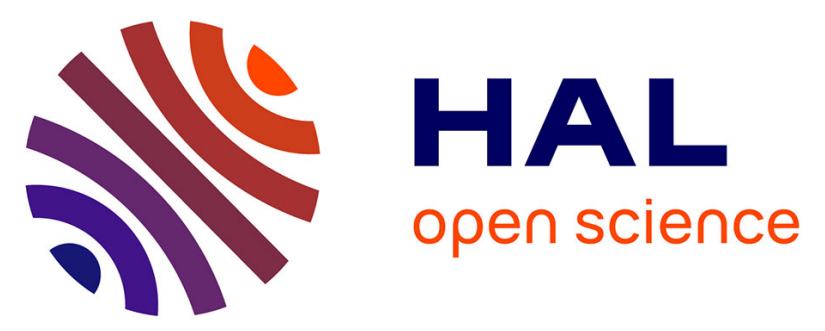

\title{
Mechanical and Thermal Properties of Sustainable Composite Building Materials Produced by the Reprocessing of Low-Density Polyethylene, Biochar, Calcium Phosphate, and Phosphogypsum Wastes
} Salifu Tahiru Azeko, Emmanuel Kwesi Arthur, Doan Pham Minh, Nathalie Lyczko, Ange Nzihou, Winston Oluwole Soboyejo

\section{To cite this version:}

Salifu Tahiru Azeko, Emmanuel Kwesi Arthur, Doan Pham Minh, Nathalie Lyczko, Ange Nzihou, et al.. Mechanical and Thermal Properties of Sustainable Composite Building Materials Produced by the Reprocessing of Low-Density Polyethylene, Biochar, Calcium Phosphate, and Phosphogypsum Wastes. Journal of Materials in Civil Engineering, 2022, 34 (2), 10.1061/(ASCE)MT.1943-5533.0004021 . hal03463869

\section{HAL Id: hal-03463869 \\ https://imt-mines-albi.hal.science/hal-03463869}

Submitted on 8 Dec 2021

HAL is a multi-disciplinary open access archive for the deposit and dissemination of scientific research documents, whether they are published or not. The documents may come from teaching and research institutions in France or abroad, or from public or private research centers.
L'archive ouverte pluridisciplinaire HAL, est destinée au dépôt et à la diffusion de documents scientifiques de niveau recherche, publiés ou non, émanant des établissements d'enseignement et de recherche français ou étrangers, des laboratoires publics ou privés. 


\title{
Mechanical and Thermal Properties of Sustainable Composite Building Materials Produced by the Reprocessing of Low-Density Polyethylene, Biochar, Calcium Phosphate, and Phosphogypsum Wastes
}

\author{
Salifu Tahiru Azeko, Ph.D. ${ }^{1}$; Emmanuel Kwesi Arthur, Ph.D. ${ }^{2}$; Doan Pham Minh³; \\ Nathalie Lyczko, Ph.D. ${ }^{4}$; Ange Nzihou ${ }^{5}$; and Winston Oluwole Soboyejo ${ }^{6}$
}

\begin{abstract}
This paper presents the results of the experimental and analytical studies of the mechanical and thermal properties of laterite composites mixed with reprocessed low-density polyethylene waste (LDPE), calcium phosphate (CaP) and phosphogypsum wastes, and biochar to form brick composites. Bricks with mixtures of $20 \%$ by volume LDPE, $15 \%$ by volume CaP, and $15 \%$ by volume gypsum were shown to have excellent compressive strength, flexural strength, and fracture toughness. The composites with $1 \%$ by volume LDPE and $15 \%$ by volume biochar had the best blend of mechanical properties, such as flexural strength and fracture toughness, after sintering for $\sim 24 \mathrm{~h}$. There was a linear association between the strength and the weight loss of the bricks. Scanning electron microscopy and optical microscopy images revealed evidence of crack bridging by LDPE particles. The laterite-LDPE composite mixed with 5\%, 10\%, and $15 \%$ by volume biochar had sintering temperatures of $\sim 850^{\circ} \mathrm{C}, \sim 720^{\circ} \mathrm{C}$, and $\sim 710^{\circ} \mathrm{C}$, respectively, after undergoing softening, cold crystallization, and cooling.
\end{abstract}

Author keywords: Laterite; Reprocessed Low-density polyethylene waste (LDPE); Biochar; Phosphogypsum; Strength; Fracture toughness; Thermal properties.

\section{Introduction}

Globally, cement and/or natural clay are used extensively in the construction of sustainable buildings (Azeko et al. 2015; Mustapha et al. 2016; Srijaroen et al. 2020). However, the production of cement results in significant carbon dioxide emissions (5\% of

\footnotetext{
${ }^{1}$ Senior Lecturer, Dept. of Mechanical Engineering, Tamale Technical Univ., Tamale, Ghana; Program in Materials Science and Engineering, Dept. of Mechanical Engineering, Worcester Polytechnic Institute, 100 Institute Rd., Worcester, MA 01609. Email: azekotahiru@gmail.com; sazeko@tatu.edu.gh

${ }^{2}$ Lecturer, Dept. of Materials Engineering, Kwame Nkrumah Univ. of Science and Technology, Kumasi, Ghana. Email: ekarthur2005@yahoo .com

${ }^{3}$ Associate Professor, Université de Toulouse, IMT Mines Albi, RAPSODEE CNRS UMR-5302, Campus Jarlard, Albi 81013 Cedex 09, France. Email: Doan.phamminh@mines-albi.fr

${ }^{4}$ Université de Toulouse, IMT Mines Albi, RAPSODEE CNRS UMR5302, Campus Jarlard, Albi 81013 Cedex 09, France. Email: nathalie .lyczko@mines-albi.fr

${ }^{5}$ Professor, Université de Toulouse, IMT Mines Albi, RAPSODEE CNRS UMR-5302, Campus Jarlard, Albi 81013 Cedex 09, France. Email: ange.nzihou@mines-albi.fr

${ }^{6}$ Professor, Dept. of Biomedical Engineering, Worcester Polytechnic Institute, WPI Life Sciences and Bioengineering Centre, 60 Prescott St., Worcester, MA 01609; Program in Materials Science and Engineering, Dept. of Mechanical Engineering, Worcester Polytechnic Institute, 100 Institute Rd., Worcester, MA 01609 (corresponding author). Email: wsoboyejo@wpi.edu
}

global $\mathrm{CO}_{2}$ emissions), which has stimulated the interest in reducing the overall use of cement in modern construction. Clay also is used extensively as a building material, although it is susceptible to cracking due to shrinkage structural loading (Liu et al. 2010). Therefore, there is a need for new construction materials that can decrease the use of cement while increasing the resistance of building materials such as clay and cement to cracking.

Artificial and/or natural wastes as well as earth-based composites have been explored as potential alternative building materials that reduce the overall use of cement in building materials (Azeko et al. 2015; Mustapha et al. 2016; Flomo et al. 2021). The composites also have enabled the recycling of agricultural wastes (natural fibers), industrial wastes [such as phosphogypsum (PG)], and human-made waste materials (such as plastics) into building materials that have attractive combinations of mechanical properties (Azeko et al. 2015; Srijaroen et al. 2020; Flomo et al. 2021). Therefore, there is the potential to integrate different types of waste materials into the development of robust and sustainable building materials.

The potential use of polyethylene as a building material can be supported by the annual global production of 80 million t polyethylene. The usefulness of polyethylene waste is about $12 \%$ (Azeko et al. 2015) which makes it difficult to form an effective disposal system. Therefore, there is a need to find suitable ways to reuse or recycle polyethylene waste for a variety of sustainable building applications.

Phosphogypsum, an industrial waste, often is discarded in bulk, without any processing, totaling 300-400 Mt/year (Hanan et al. 2009). The precipitation of these wastes usually is associated with multiple loadings of radionuclides and heavy metals (Macíasa et al. 2017). Rashad (2017) showed that the heavy metals in PG are safe for use in construction applications, especially in affordable homes. 
Table 1. Mechanical properties of earth bricks/blocks from previous studies

\begin{tabular}{|c|c|c|c|c|}
\hline Type of blocks & $\begin{array}{l}\text { Compressive strength } \\
\text { (MPa) }\end{array}$ & $\begin{array}{l}\text { Flexural strength } \\
\quad(\mathrm{MPa})\end{array}$ & $\begin{array}{l}\text { Fracture toughness } \\
\quad(\mathrm{MPa} \sqrt{m})\end{array}$ & Reference \\
\hline Laterite reinforced with polyethylene bricks & 4.1 & 6.1 & 0.76 & Azeko et al. $(2018,2015)$ \\
\hline $\begin{array}{l}\text { Laterite and clay reinforced with natural straw } \\
\text { bricks }\end{array}$ & 3.03 & 9 & 1.4 & Kabiru et al. (2016) \\
\hline $\begin{array}{l}\text { Waste sisal and Eucalyptus grandis pulp } \\
\text { cement composites }\end{array}$ & Not measured & 19.2 & 0.64 & Savastano et al. (2005) \\
\hline $\begin{array}{l}\text { Cement blocks reinforced with sisal and } \\
\text { banana pulp fibers }\end{array}$ & Not measured & 20 & 1.5 & Savastano et al. (2000) \\
\hline Concrete blocks reinforced with crumb rubber & 23 & Not measured & 0.39 & Sukontasukkul and Chaikaew (2006) \\
\hline Concrete block & 36 & Not measured & 0.25 & Sukontasukkul and Chaikaew (2006) \\
\hline Fly ash concrete & 26.7 & 3.6 & Not measured & Siddique (2004) \\
\hline Cement-stabilized compressed earth blocks & 4.13 & Not measured & Not measured & Walker and Stace (1997) \\
\hline
\end{tabular}

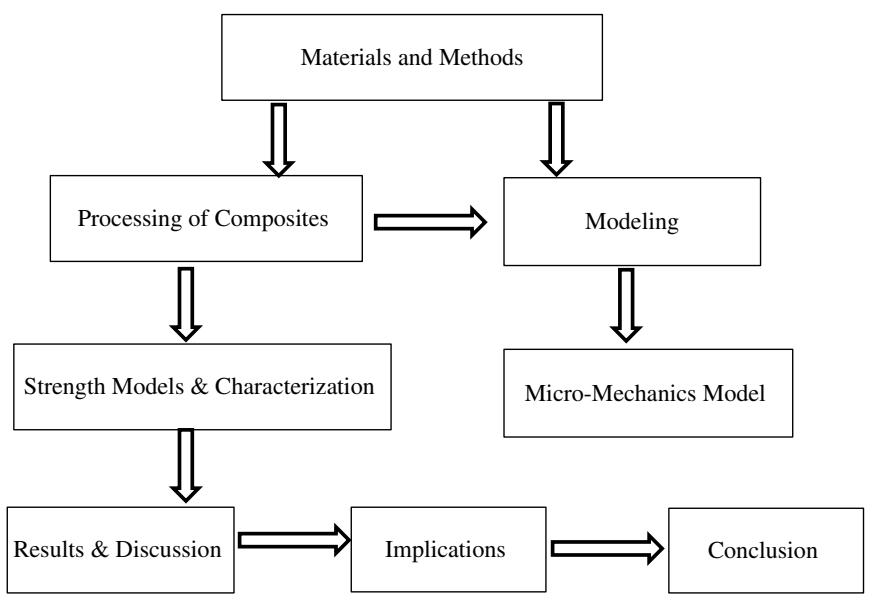

Fig. 1. Flowchart of research approach.

Biochar, a carbon-rich material, often is produced from organic materials that burn under little or no-oxygen conditions due to pyrolysis, hydrothermal carbonization, gasification (Cha et al. 2016), flash carbonization (Nunoura et al. 2006), and torrefaction (Benavente and Fullana 2015). Some applications of biochar include water purification and energy storage (Yang et al. 2017).

The use of cement in modern buildings are expensive and environmentally unfriendly, and therefore there is a need to replace this material partially with other natural and artificial wastes such as slags (Savastano et al. 2001), straws (Mustapha et al. 2016), banana fibers (Savastano et al. 2000), discarded tires (Sukontasukkul and Chaikaew 2006), ash (Saddique 2004), termite soil (Mahamat et al. 2021), and polyethylene (Azeko et al. 2015c, 2018; Flomo et al. 2021) without causing additional pollution. These wastes when incorporated into cement-based materials have enhanced mechanical properties such as compressive strength, fracture toughness, and flexural strength that are similar to those of conventional cementbased structures (Table 1). Although these methods have significantly increased the mechanical properties of reinforced blocks/ bricks, there still is a need to recycle potential environmentally unfriendly materials such as polyethylene, calcium phosphate, and phosphogypsum wastes for sustainable building applications.

This paper presents the results of an experimental and theoretical study of the mechanical properties of sustainable building materials that incorporate recycled plastics, calcium phosphate, and phosphogypsum into laterite (clay with high iron oxide content) composite materials. Low-density polyethylene (LDPE) was powderized and mixed in different proportions with laterite, calcium phosphate, phosphogypsum, and cement to form unique composites for sustainable building applications. The strength and fracture toughness of the resulting composites were studied using a combination of experiments and micromechanical models. The implications of the results were discussed for the development of sustainable building materials.

The research approach for this work is illustrated in Fig. 1.

Modeling and composite processing played an integral part in materials and methods. Strength models and characterization, results and discussion, implications of results, and conclusions depended on the type of materials selected for processing of the polyethylene composites.

\section{Modeling}

The modified mean field (M-T) was the basis for the development of the micromechanical composite model (Weng 2011; Guo et al. 2014). This model was used in estimating the overall stress and strain in bimodal LDPE bricks. The secant elastic modulus and secant Poisson's ratio for the $j$ th phase can be expressed as

$$
E^{S(j)}=\frac{E^{(j)}}{1+\frac{E^{(j)} \varepsilon^{(j)}}{\sigma_{\text {flow }}^{(j)}}\left(\frac{\sigma_{\text {l1 }}^{(j)}}{\sigma_{\text {flow }}^{(j)}}\right)^{m_{0}-1}}
$$

and

$$
v^{S(j)}=\frac{1}{2}-\left(\frac{1}{2}-v^{(j)} \frac{E^{S(j)}}{E^{(i)}}\right)
$$

where $E^{(j)}$ and $v^{(j)}=$ elastic modulus and Poisson's ratio, respectively, of $j$ th phase. The matrix and coarse grains phase are denoted 0 and 1 , respectively. The resultant secant bulk and shear moduli for the $j$ th phase are considered and this satisfies the respective isotropic expressions

$$
\eta^{S(j)}=\frac{E^{S(j)}}{3\left[\left(1-2 \nu^{S(j)}\right)\right]}
$$

and

$$
\varphi^{S(j)}=\frac{E^{S(j)}}{\left[2\left(1+\nu^{S(j)}\right)\right]}
$$

Suppose that there is a boundary displacement in the composite with a homogenous strain, $\bar{\varepsilon}$; the hydrostatic and deviatoric strains of the constituent phases relationship are (Weng 2011; Guo et al. 2014) 


$$
\begin{aligned}
& \varepsilon_{i j}^{(0)^{\prime}}=\frac{\gamma_{0}^{s}\left(\mu_{1}-\mu_{0}^{s}\right)}{c_{0} \gamma_{0}^{s}\left(\mu_{1}-\mu_{0}^{s}\right)+\mu_{0}^{s}} \bar{\varepsilon}_{i j}^{\prime}-\frac{c_{1} \gamma_{0}^{s} \mu_{1}}{c_{0} \gamma_{0}^{s}\left(\mu_{1}-\mu_{0}^{s}\right)+\mu_{0}^{s}} \varepsilon_{i j}^{p(1)} \\
& \varepsilon_{i j}^{(1)^{\prime}}=c_{c_{0} \gamma_{0}^{s}\left(\mu_{1}-\mu_{0}^{s}\right)+\mu_{0}^{s}} \bar{\varepsilon}_{i j}^{\prime}+\frac{c_{0} \gamma_{0}^{s} \mu_{1}}{c_{0} \gamma_{0}^{s}\left(\mu_{1}-\mu_{0}^{s}\right)+\mu_{0}^{s}} \varepsilon_{i j}^{p(1)}
\end{aligned}
$$

where the mean stress components of the matrix phase and inclusions are given by

$$
\begin{gathered}
\sigma_{i j}^{(1)^{\prime}}=\frac{2 \mu_{0}^{s} \mu_{1}\left[\bar{\varepsilon}_{i j}^{\prime}-\left(1-c_{0} \gamma_{0}^{s}\right) \varepsilon_{i j}^{p(1)}\right]}{c_{0} \gamma_{0}^{s}\left(\mu_{1}-\mu_{0}^{s}\right)+\mu_{0}^{s}} \\
\sigma_{i j}^{(0)^{\prime}}=\frac{2 \mu_{0}^{s}\left\{\left[\gamma_{0}^{s}\left(\mu_{1}-\mu_{0}^{s}\right)+\mu_{0}^{s}\right] \bar{\varepsilon}_{i j}^{\prime}-c_{1} \gamma_{0}^{s} \mu_{1} \varepsilon_{i j}^{p(1)}\right\}}{c_{0} \gamma_{0}^{s}\left(\mu_{1}-\mu_{0}^{s}\right)+\mu_{0}^{s}}
\end{gathered}
$$

where $f_{i}=$ volume fraction of $i$ th phase; and $\alpha$ and $\gamma=$ components of Eshelby's tensor for spherical inclusions, as follows:

$$
S_{0}^{s}=\left(\alpha_{0}^{s}, \gamma_{0}^{s}\right), \quad \text { where } \alpha_{0}^{s}=\frac{1+v_{0}^{s}}{3\left(1-v_{0}^{s}\right)}, \quad \text { and } \quad \gamma_{0}^{s}=\frac{2\left(4-5 v_{0}^{s}\right)}{15\left(1-v_{0}^{s}\right)}
$$

Therefore, the dilatational and deviatoric stresses and strains of the composite are connected by

$$
\begin{gathered}
\bar{\sigma}_{k k}=3 k_{0}\left[1+\frac{c_{1}\left(k_{1}-k_{0}\right)}{c_{0} \alpha_{0}^{s}\left(k_{1}-k_{0}\right)+k_{0}}\right] \bar{\varepsilon}_{k k} \\
\sigma_{i j}^{-1}=2 \mu_{0}^{s}\left\{\left[1+\frac{c_{1}\left(\mu_{1}-\mu_{0}^{s}\right)}{c_{0} \gamma_{0}^{s}\left(\mu_{1}-\mu_{0}^{s}\right)+\mu_{0}^{s}}\right] \varepsilon_{i j}^{-1}\right. \\
\left.-\frac{c_{1} \mu_{1}}{c_{0} \gamma_{0}^{s}\left(\mu_{1}-\mu_{0}^{s}\right)+\mu_{0}^{s}} \varepsilon_{i j}^{p(1)}\right\}
\end{gathered}
$$

\section{Materials and Methods}

\section{Formulation and Processing of Composite}

Laterite was acquired from the Building and Technology Department at Tamale Technical University (TaTU) in Tamale, Northern Region, Ghana. The as-received laterite initially was air-dried and crushed/milled with reduced particle sizes of approximately $900 \pm 0.03 \mu \mathrm{m}$. The particle-size distributions of the laterite after the sieve analysis are presented in Fig. 2. The LDPE particles were

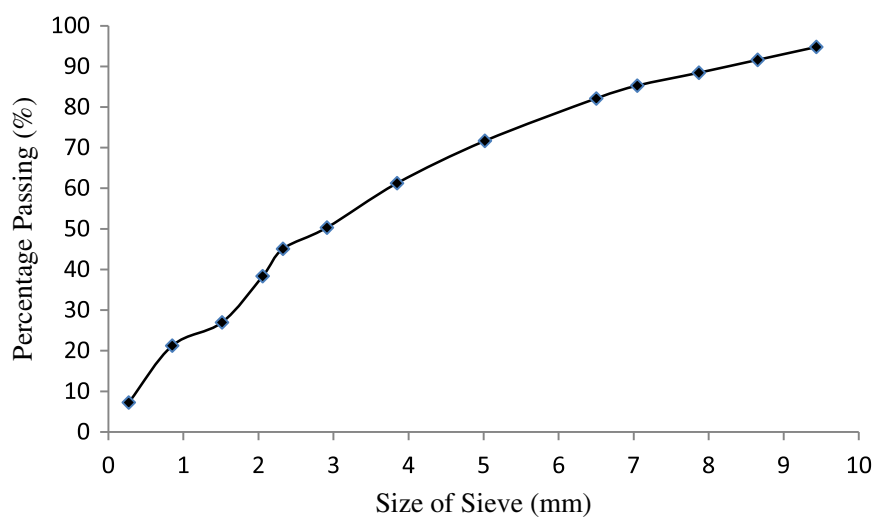

Fig. 2. Particle-size distribution curve of laterite. produced according to the procedure used by Azeko et al. (2015a, 2018). The powdered LDPE was subjected to sieve analysis to obtain an average size of $900 \pm 0.03 \mu \mathrm{m}$. Portland cement (Savannah Cement Company, Buipe, Northern Ghana) was used as a binding material.

The matrix material (i.e., combination of laterite and cement) was mixed with the LDPE particles and calcium phosphate in one composite, then LDPE particles and gypsum as well as LDPE particles in another composite, and finally with calcium phosphate and gypsum in the third composite in different proportions. The LDPE particles were mixed mechanically using $10 \%, 15 \%$, and $20 \%$ by volume. These were mixed with $150 \mathrm{~mL}$ water for $5 \mathrm{~min}$. The mixed samples were molded into rectangular-shaped samples with dimensions of $100 \times 25 \times 12.5 \mathrm{~mm}$. A uniform pressure of about $20 \mathrm{kN}$ was applied to the molds for $5 \mathrm{~min}$. The prepared samples then were cut into pieces with dimensions of $60 \times 10 \times 5 \mathrm{~mm}$ for flexural strength and fracture toughness measurements and with dimensions of $20 \times 20 \times 20 \mathrm{~mm}$ for compressive strength measurement. All the samples (for flexural, compressive, and fracture toughness) were carefully ground with $\mathrm{P} 80 \mathrm{SiC}$ abrasive papers (CarbiMet, Buehler, Uzwil, Switzerland), at $350 \mathrm{rpm}$ to produce composites with different proportions.

Similar procedures were used for molding the $100 \%$ by volume laterite; $20 \%$ by volume ordinary portland cement (Savannah Cement Company, Buipe, Northern Ghana) was used throughout the sample preparation with the exception of the samples with $100 \%$ laterite.

The prepared composite samples were air-dried at room temperature $\left(25^{\circ} \mathrm{C}-30^{\circ} \mathrm{C}\right)$ for 2 weeks and then dried in an electric oven (Memmert, Schwabach, Germany) at $100^{\circ} \mathrm{C}$ for $24 \mathrm{~h}$. Samples then were subjected to various forms of analysis, including flexural strength, compressive strength, resistance curve, fracture toughness, scanning electron microscopy (SEM), differential scanning calorimetry (DSC) and X-ray diffraction (XRD).

\section{Composite Preparation for Thermal Energy Storage}

Various formulations of the composites used for thermal energy storage applied in buildings are listed in Table 2. This involved mixing different weight percentages of pure laterite with biochar, laterite with gypsum, as well as laterite, biochar, and gypsum with LDPE, respectively, to investigate the strength and thermal energy storage capabilities for building applications. The biochar was obtained from the gasification of wood biomass. The biochar was ground and sieved to obtain average particle sizes of approximately $160 \mu \mathrm{m}$. The biochar then was mixed in volume percentages of $5 \%$, $10 \%$, and $15 \%$ with the LDPE at $1 \%$ and $2 \%$ by volume, and gypsum was mixed uniformly at $20 \%$ by volume. The mixtures

\begin{tabular}{|c|c|c|c|c|}
\hline No. & $\begin{array}{c}\text { Laterite } \\
\text { (\% by volume) }\end{array}$ & Laterite $(\mathrm{g})$ & $\begin{array}{c}\text { Biochar } \\
\text { (\% by volume) }\end{array}$ & Biochar $(\mathrm{g})$ \\
\hline 1 & 95 & 285 & 5 & 15 \\
\hline 2 & 90 & 270 & 10 & 30 \\
\hline 3 & 85 & 255 & 15 & 45 \\
\hline
\end{tabular}
were mixed mechanically with $150 \mathrm{~mL}$ water for $5 \mathrm{~min}$ and then extruded with a bench extruder (Reber, Correggioverde di Dosolo, Italy) to obtain composites with rectangular dimensions of $60 \times$ $30 \times 10 \mathrm{~mm}$. The prepared samples were cut into rectangular dimensions $(60 \times 10 \times 5 \mathrm{~mm})$ and ground with P80 SiC abrasive papers (CarbiMet, Buehler, Uzwil, Switzerland) at $350 \mathrm{rpm}$.

Table 2. Composition of laterite and biochar 
A Phillips P-analytical X'pert Pro MPD diffractometer was used to collect the XRD data. The radiation source ray used was copper (Cu) with wavelength $K_{\alpha}$ of $1.543 \AA$. A nickel filter was used to remove the $\mathrm{Cu} K_{\beta}$ ray. The operating conditions for the apparatus were $45 \mathrm{kV}$ and $40 \mathrm{~mA}$. The diffractogram was recorded from $10^{\circ}$ to $75^{\circ}$ in $2 q$. The steps size was $0.017^{\circ}$ in $2 q$ and the scan step-time was 29.89 s. The phase identification was carried out from the databases of JCPDS and COD.

\section{Thermogravimetric Analysis and Differential Scanning Calorimetry}

Thermal analyses of the formulated composite samples were carried out using thermogravimetric analysis (TGA)/DSC equipment

(SDT Q600, TA Instruments). About 50-100 mg of the solid was heated from ambient temperature to $1,100^{\circ} \mathrm{C}$ at $5^{\circ} \mathrm{C} / \mathrm{min}$, followed by an isotherm for $30 \mathrm{~min}$. All the TGA/DSC analyses were made under atmospheric conditions with a $100 \mathrm{~mL} \cdot \mathrm{min}^{-1}$ flow rate. The crucible used for the analysis of the samples was made from alumina, and the reference was an empty alumina pan.

\section{Thermomechanical Analysis}

Thermomechanical analyses (TMA) were carried out using a TMA Setsys (Setaram). A sample with a mass of $10 \mathrm{~g}$ was heated from $30^{\circ} \mathrm{C}$ to $1,100^{\circ} \mathrm{C}$ at $5^{\circ} \mathrm{C} / \mathrm{min}$, followed by an isotherm for $30 \mathrm{~min}$,

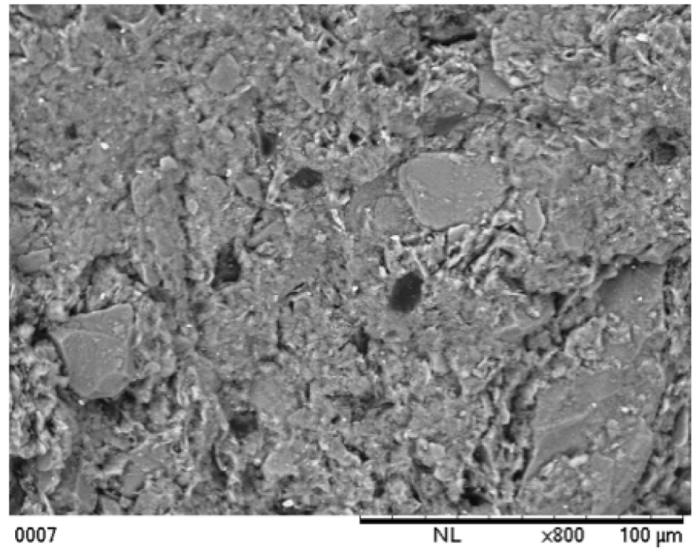

$L+20 \%$ biochar

(a)

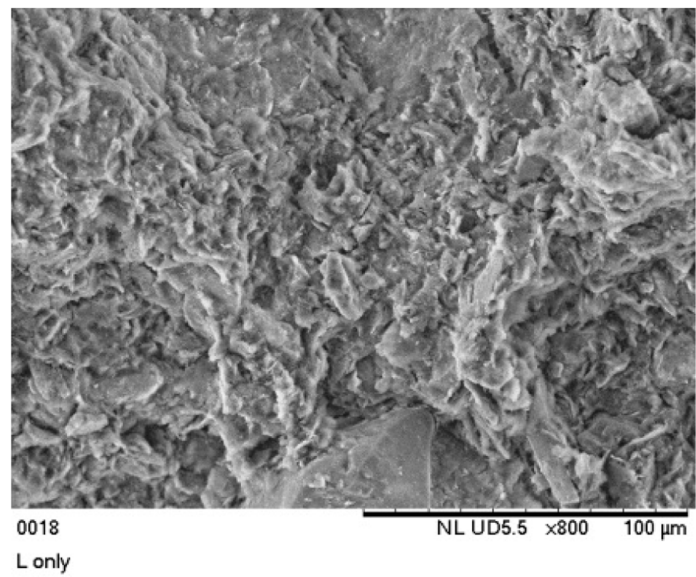

(c) and then slowly cooled to $30^{\circ} \mathrm{C}$. The crucible used for the analysis of the samples was made from alumina, and the reference was an empty alumina pan.

\section{Results and Discussion}

\section{Microstructural and XRD Analysis}

Micrographs of the laterite/cement matrix and the PE, gypsum, and calcium phosphate composites are presented in Figs. 3(a-d) and 4(a-d). These SEM images clearly indicate how different particles interacted within each composite microstructure. Figs. 3(a) and 4(c and d) show porous microstructures, which means that the particles are bonded loosely at the microscopic scale. This negatively affects the composite overall strength. However, Figs. 3(d) and 4( $\mathrm{a}$ and $\mathrm{b})$ exhibit particles that are bonded closely within the microstructure, and are likely to have high strength, Evidence of multiple cracks, emanating from a parent crack, and smooth transgranular cracks are presented in Figs. 5(a-d).

The XRD results obtained for the composites are presented in Figs. 6(a-c). The mixing of laterite with gypsum, PE, or biochar did not modify the obtained diffractograms [Figs. 6(b-c)]. However, there were distinct diffractograms for laterite, $\mathrm{PE}$, and biochar [Fig. 5(a)].

In the XRD analysis, $\mathrm{AlSiO}_{2}(\mathrm{OH})_{2}$, which is in the kaolinite group, was identified. This compound has a hexagonal plate-like

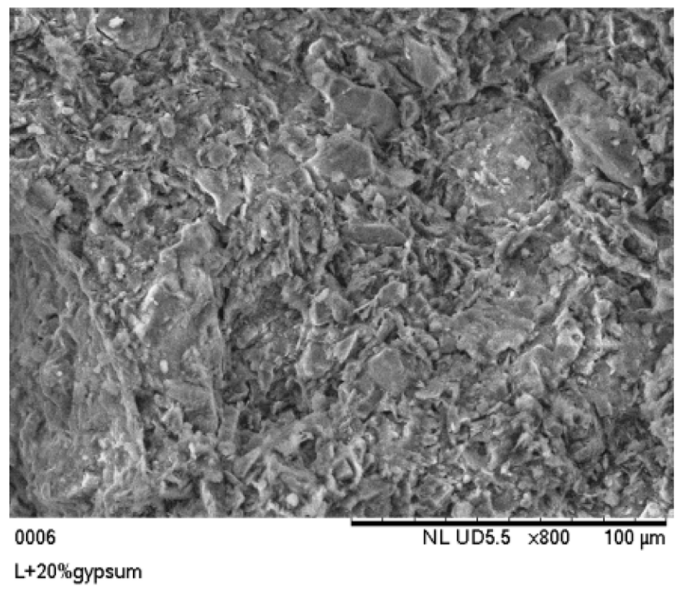

(b)

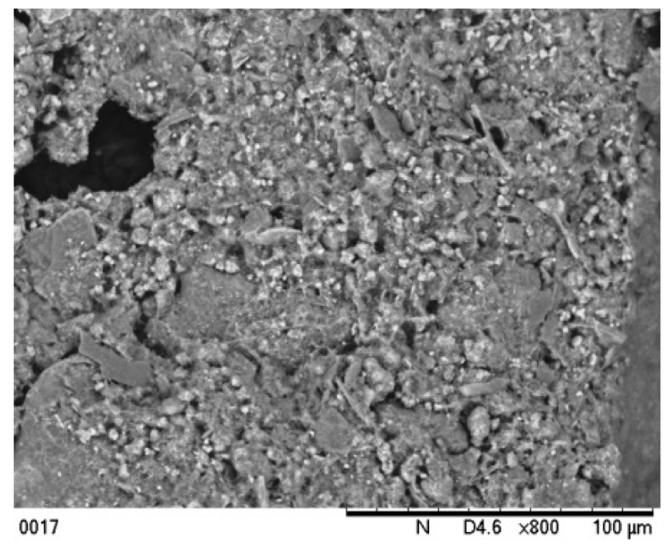

$\mathrm{L}+10 \% \mathrm{PE}+20 \% \mathrm{CaP}$

(d)

Fig. 3. SEM images of (a) laterite with $20 \%$ biochar; (b) laterite with $20 \%$ gypsum; (c) laterite only; and (d) laterite with $10 \%$ LDPE and $20 \%$ CaP. 


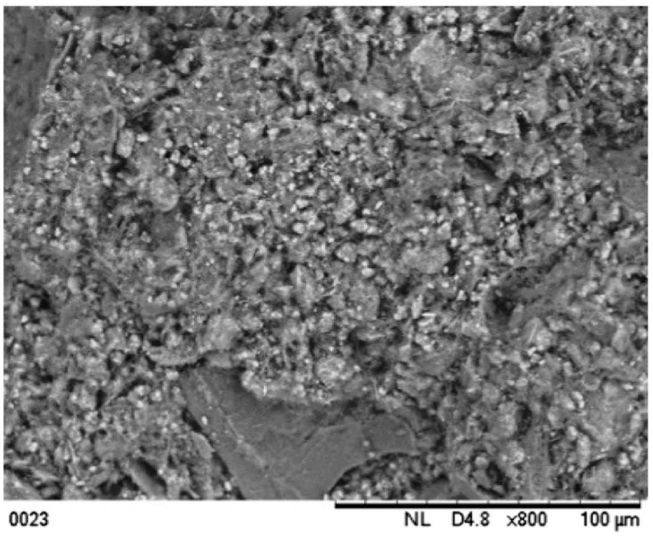

$L+15 \% \mathrm{PE}+25 \% \mathrm{CaP}$

(a)

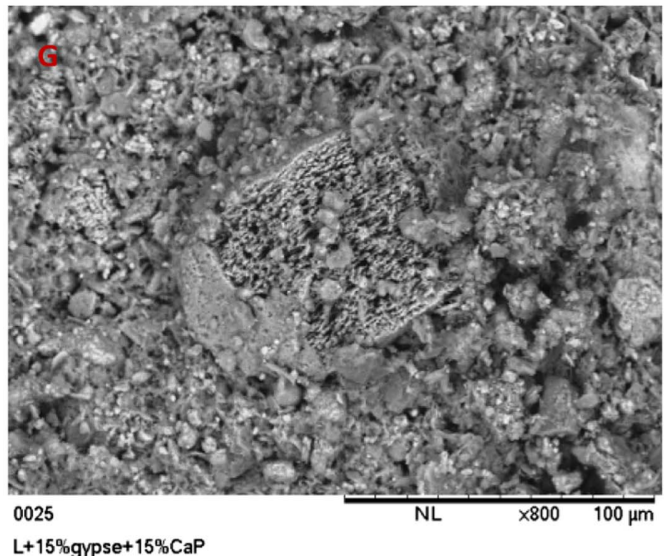

(c)

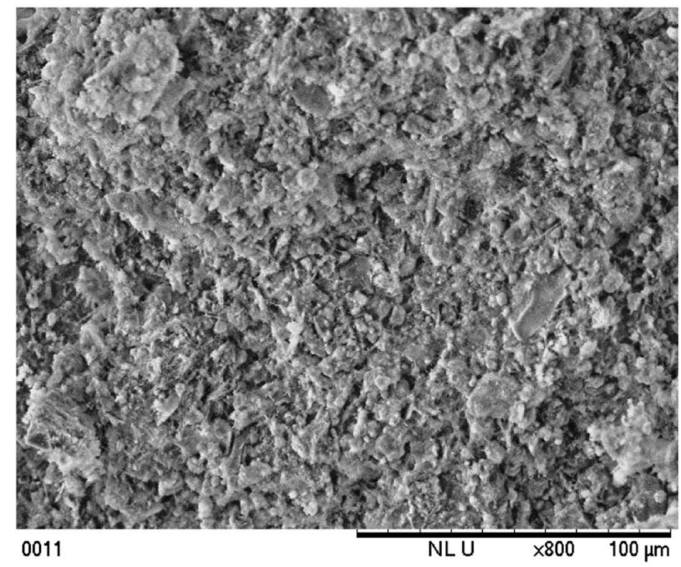

(b)

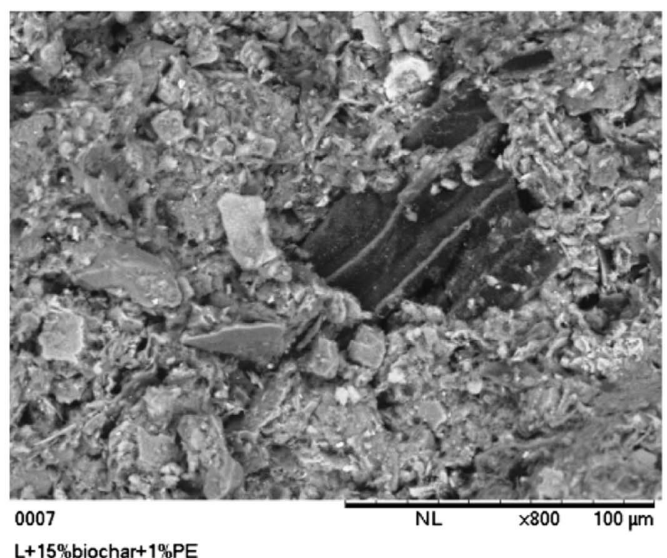

(d)

Fig. 4. SEM images of (a) laterite with 15\% LDPE and 25\% CaP; (b) laterite with $20 \% \mathrm{LDPE}$ and $30 \% \mathrm{CaP}$; (c) laterite with $15 \%$ gypsum and $15 \% \mathrm{CaP}$; and (d) laterite with $15 \%$ biochar and $1 \%$ LDPE.

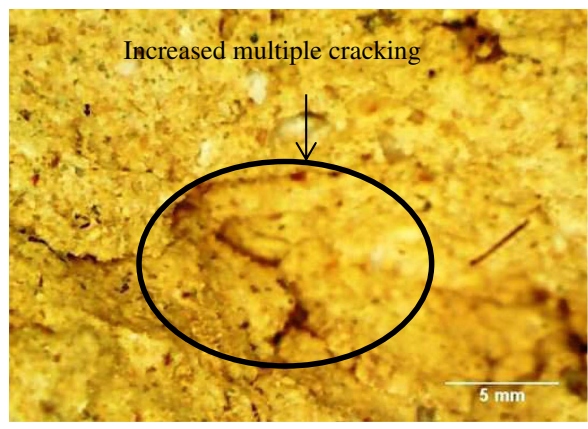

(a)

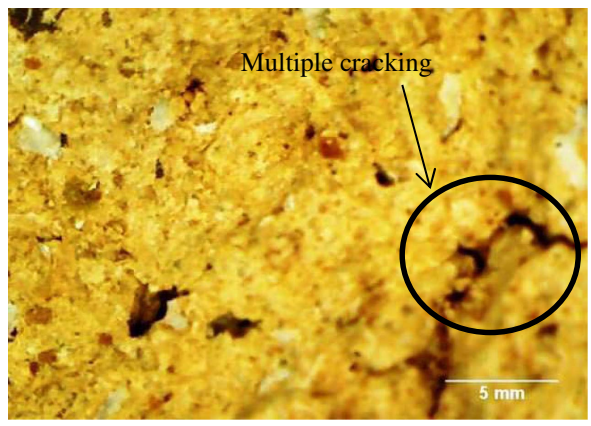

(c)

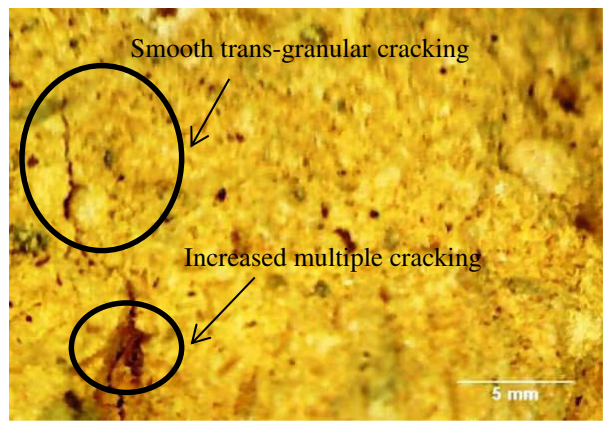

(b)

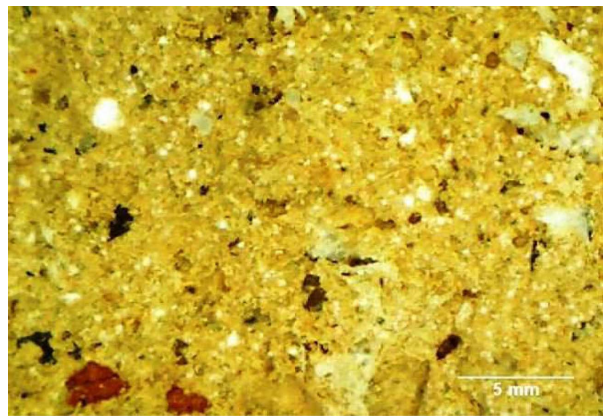

(d)

Fig. 5. Optical images of (a) laterite; (b) laterite with LDPE and biochar; (c) laterite with gypsum; and (d) laterite with LDPE, CaP, and gypsum. 

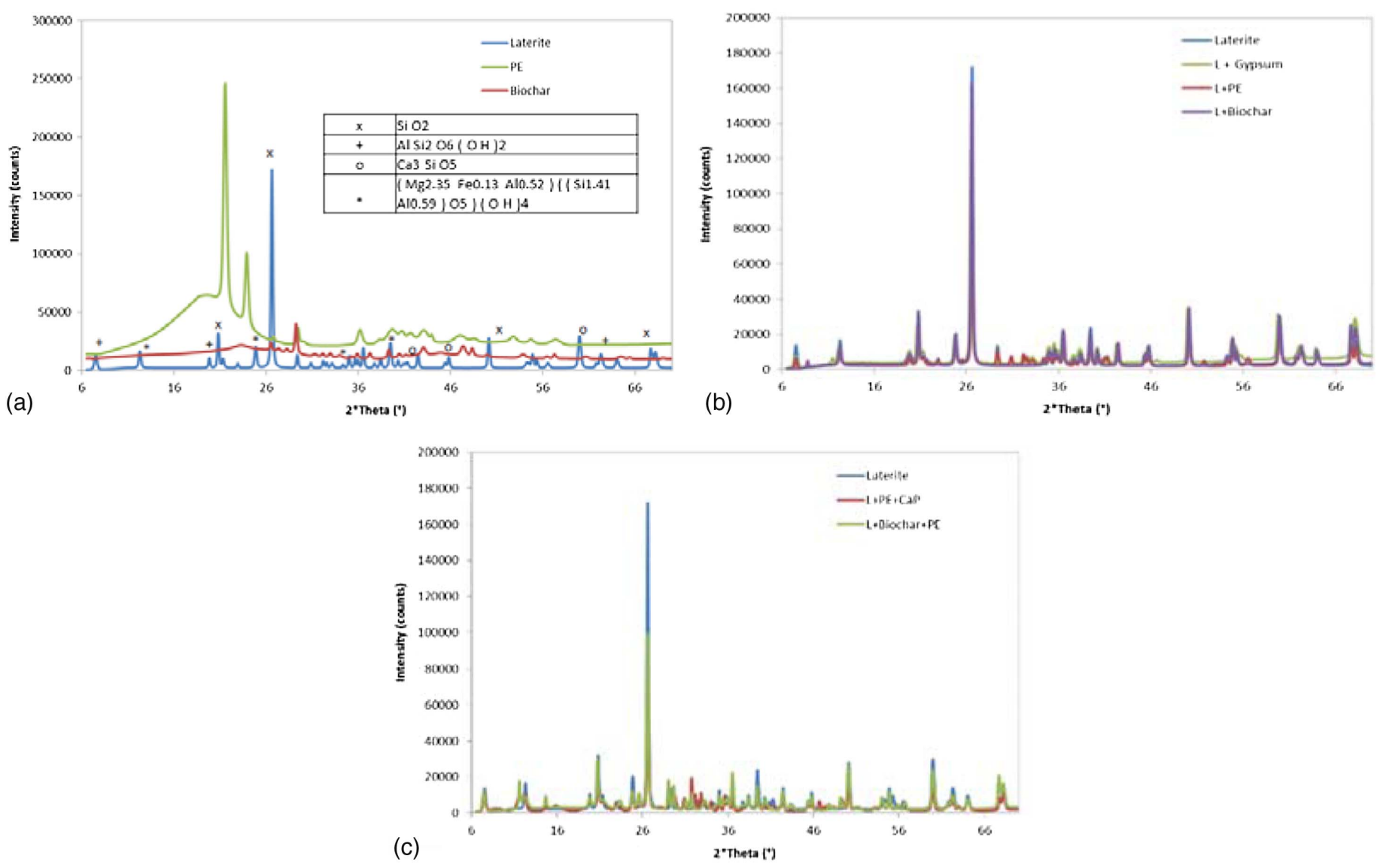

Fig. 6. XRD analysis of (a) laterite, LDPE and biochar; (b) laterite, laterite with gypsum, laterite with PE, and laterite with biochar; and (c) laterite, laterite with LDPE and calcium phosphate, and laterite with biochar and LDPE.

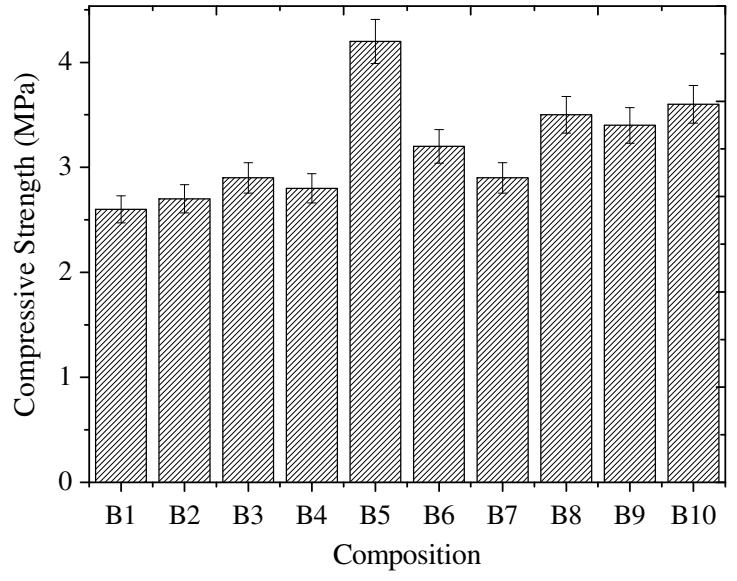

Fig. 7. Compressive strengths of laterite composites.

shape with higher stacking regularity in varying degrees. The XRD analysis also revealed the presence of a second compound, $\mathrm{Mg}_{2.35} \mathrm{Fe}_{0.13} \mathrm{Al}_{0.52}$, which was attributed to reactions between the portland cement and the biochar. This compound is responsible for quick setting and rapid hardening (i.e., it is a good binder), leading to the higher overall strength of the composite. The toughening and strengthening mechanisms of the polyethylene and phosphogypsum in the bricks are a major scientific contribution.

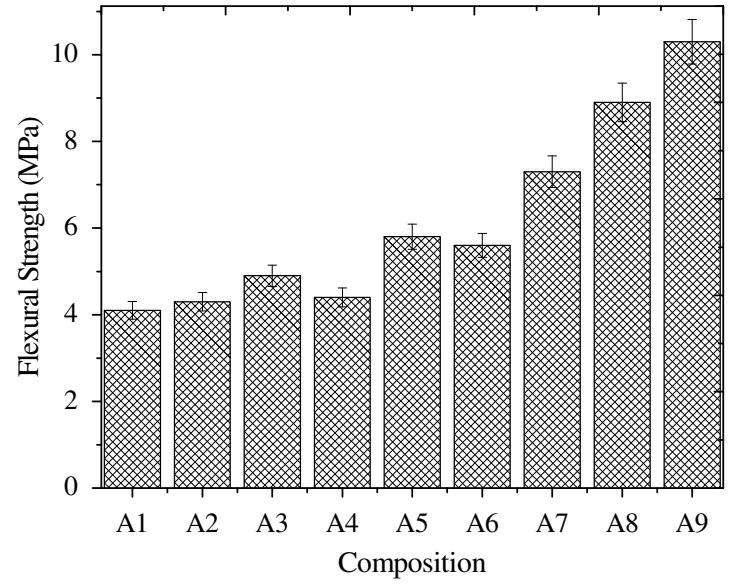

Fig. 8. Flexural strengths of laterite composites.

\section{Compressive Strength}

Fig. 7 presents the measured compressive strengths values obtained for all the tested samples. The compressive strength results showed that the $100 \%$ laterite composition had a compressive strength of $\sim 2.82 \pm 0.01 \mathrm{MPa}$ after drying in an oven for $24 \mathrm{~h}$. The strength o f the composites increased to $\sim 3.5 \pm 0.032 \mathrm{MPa}$ and $\sim 3.6 \pm$ $0.231 \mathrm{MPa}$ for composite mixtures of $70 \%$ by volume laterite 
$+10 \%$ by volume $\mathrm{LDPE}=20 \%$ gypsum and of $60 \%$ by volume laterite $+15 \%$ by volume LDPE $+12.5 \%$ by volume gypsum $+12.5 \%$ by volume calcium phosphate, respectively, after drying for $24 \mathrm{~h}$ in an electric oven. The highest compressive strength of the composites was achieved $(\sim 4.3 \pm 0.02 \mathrm{MPa})$ by increasing the LDPE to $20 \%$ by volume and increasing the gypsum and

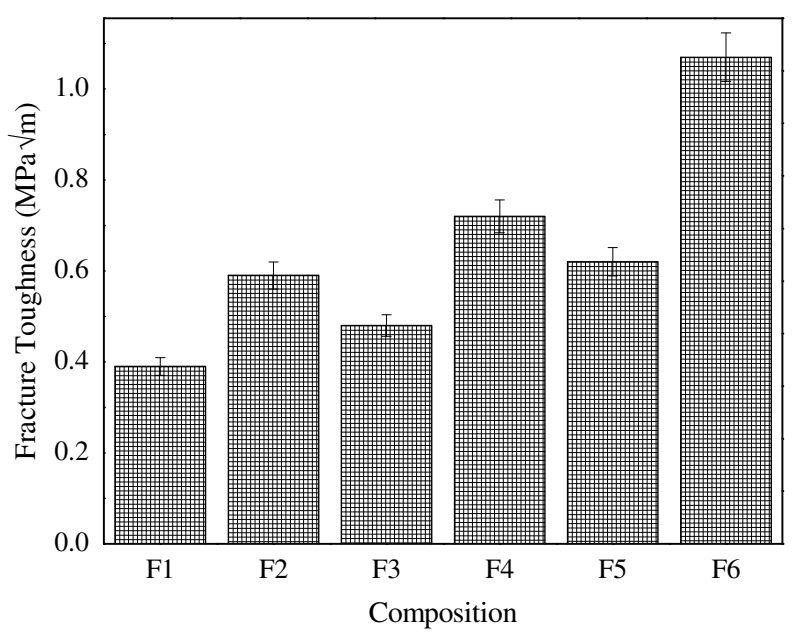

Fig. 9. Fracture toughness of laterite composites.

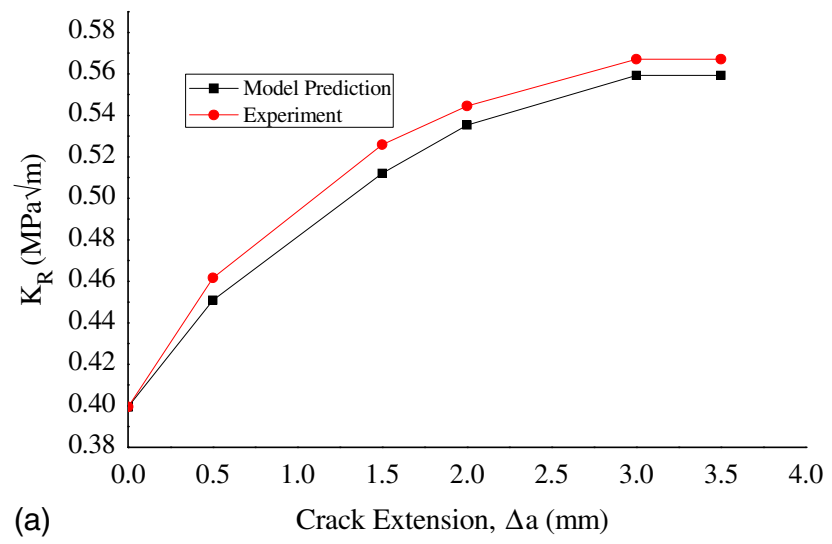

calcium phosphate to $15 \%$ by volume each. This tremendous increase in compressive strength was possible due to the effective binding of LDPE particles with gypsum and calcium phosphate particles within the microstructure.

Poorer strengths of the composites $(2.6 \pm 0.03 \mathrm{MPa})$ were obtained for the composites reinforced with $10 \%$ by volume LDPE and $20 \%$ by volume calcium phosphate. This was attributed to the presence of voids unfilled by LDPE particles and weak linkages due to matrix-matrix interactions of calcium phosphate particles. The trends of the measured compressive strength results in Fig. 7 are consistent with those of related work on earth-based brick composites (Table 1). The recycling of polyethylene and phosphogypsum wastes contributed to the overall strengthening mechanism in the bricks.

\section{Flexural Strength}

Fig. 8 shows the flexural strengths obtained for all of the tested formulated composite samples. The flexural strength results show that the $100 \%$ laterite sample had a flexural strength of $4.1 \pm$ $0.02 \mathrm{MPa}$ after drying in an electric oven for $24 \mathrm{~h}$. This value increased significantly to $\sim 6.0 \pm 0.02 \mathrm{MPa}$ for mixtures of $50 \%$ by volume laterite, $20 \%$ by volume LDPE, $15 \%$ by volume gypsum, and $15 \%$ by volume calcium phosphate after drying for $24 \mathrm{~h}$ in an electric oven.

The flexural strength of the laterite increased with the inclusion of $1 \%$ by volume LDPE and $15 \%$ by volume biochar after sintering

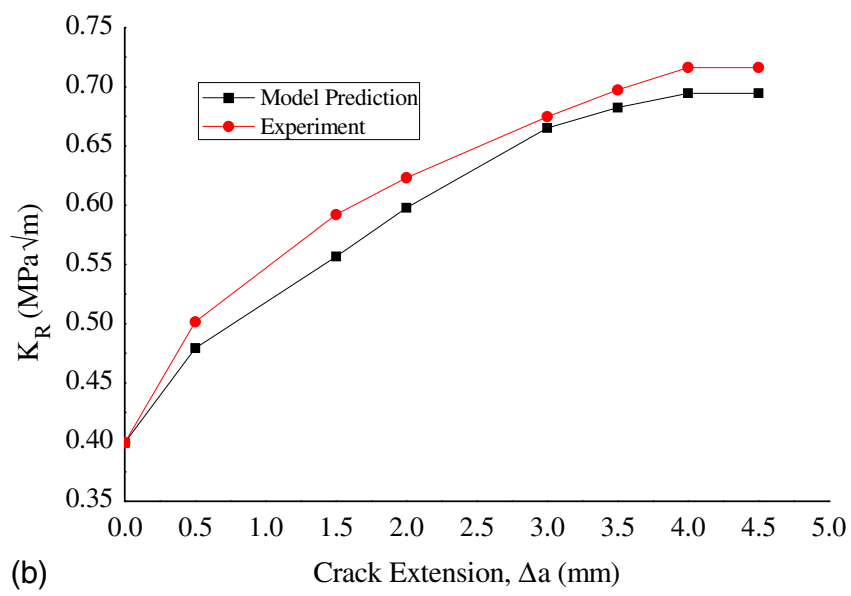

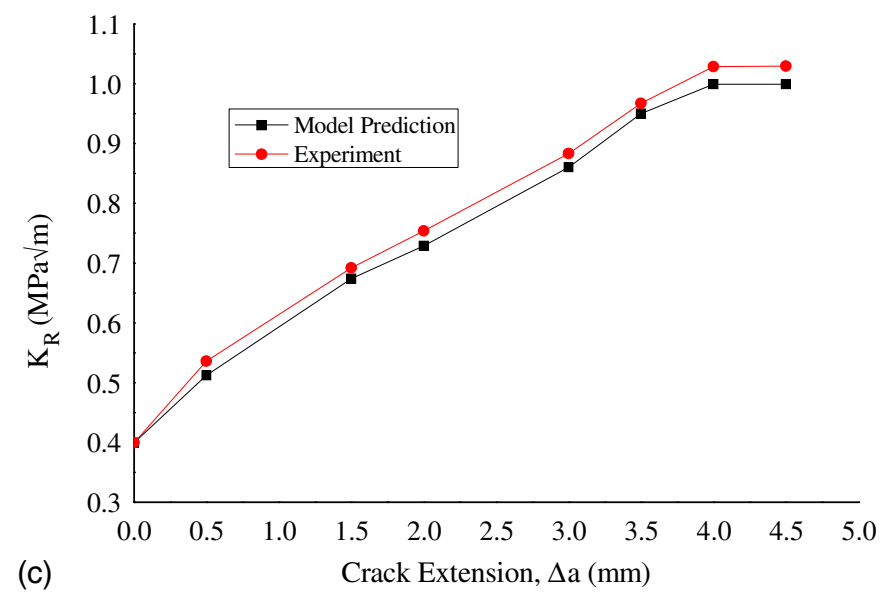

Fig. 10. Resistance curve behavior of (a) $94 \%$ by volume laterite $+1 \%$ by volume LDPE $+5 \%$ by volume biochar; (b) $89 \%$ by volume laterite $+1 \%$ by volume LDPE $+10 \%$ by volume biochar; and (c) $84 \%$ by volume laterite $+1 \%$ by volume LDPE $+15 \%$ by volume biochar. 
for 24 hours. The laterite composite reinforced with $1 \%$ by volume LDPE and $15 \%$ by volume biochar had the highest flexural strengths, $\sim 10.1 \pm 0.02 \mathrm{MPa}$ (Fig. 8). This was because of the dehydration caused by the sintering. Such dehydration should harden and strengthen the composite. In addition, during the sintering process, some of the LDPE particles melted and filled the voids left behind after hydration, resulting in overall composite strengthening.

Poorer flexural strengths of $\sim 4.0 \pm 0.03 \mathrm{MPa}$ were obtained for composites reinforced with $10 \%$ by volume LDPE and $20 \%$ by volume calcium phosphate. Similar to the results obtained for the compressive strength results, this trend was attributed to the existence of voids unfilled by LDPE particles and weak linkages due to matrix-matrix interactions of calcium phosphate particles. The trends in the flexural strength results are shown in Fig. 8. These are consistent with results of related work on earth-based brick composites (Table 1). It is clear from these results that the recycling of polyethylene and phosphogypsum wastes contributes to the overall strengthening of the bricks.

\section{Fracture Toughness and Fracture Modes}

Fig. 9 shows the measured fracture toughness values obtained for all the tested samples. The fracture toughness of the formulated composite samples increased with LDPE and biochar volume percentages ( $1 \%$ by volume and $15 \%$ by volume, respectively).
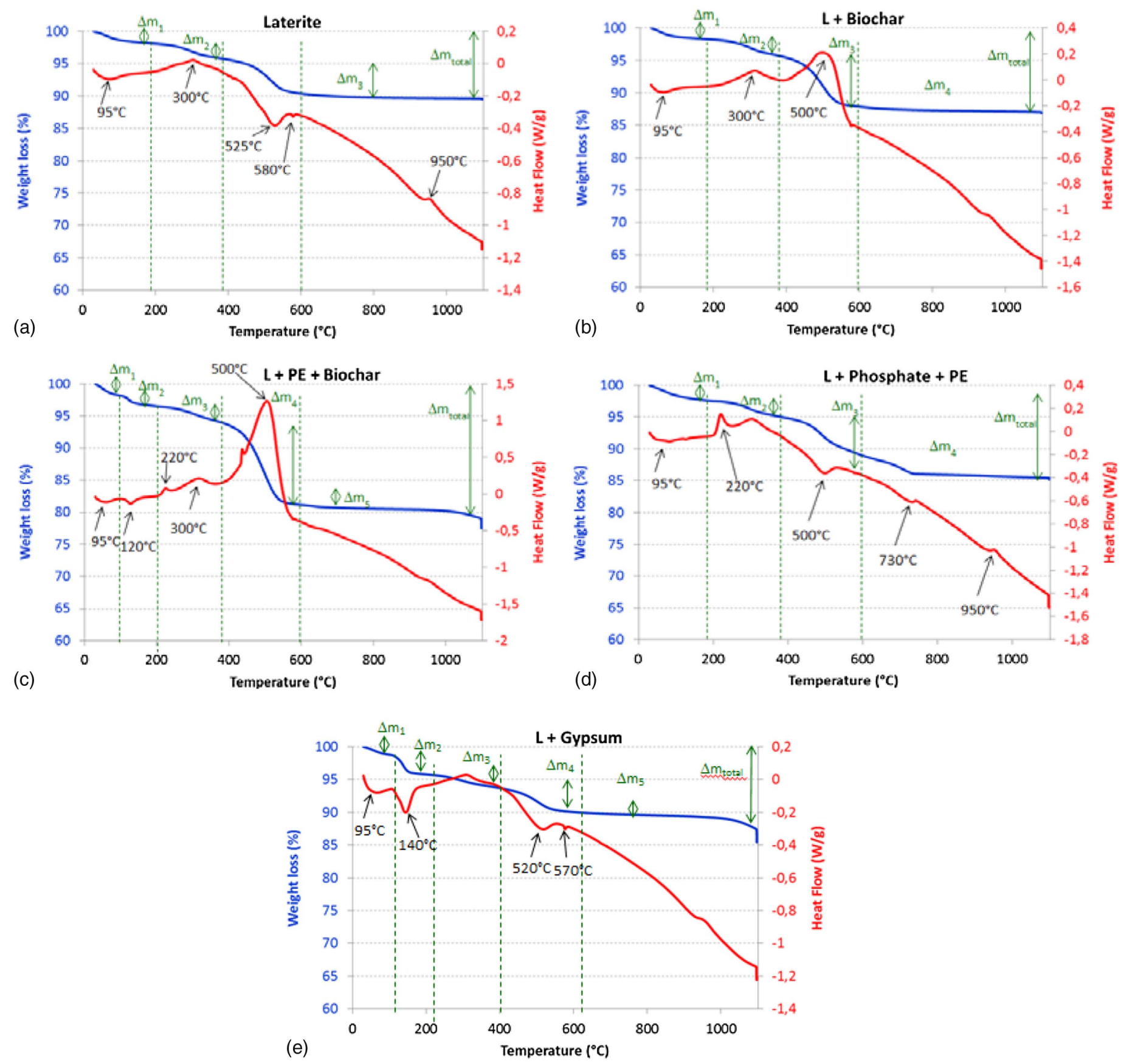

Fig. 11. TGA/DSC analysis of (a) laterite; (b) laterite with biochar; (c) laterite with LDPE and biochar; (d) laterite with phosphate and biochar; and (e) laterite with gypsum. 
The highest fracture toughness, $\sim 1.1 \pm 0.04 \mathrm{MPa} \sqrt{ } m$, was obtained for the laterite composite reinforced with $1 \%$ by volume LDPE and $15 \%$ by volume biochar (Fig. 9). Furthermore, the composite formulation with $10 \%$ by volume LDPE and $20 \%$ by volume calcium phosphate had the lowest fracture toughness, $\sim 0.4 \pm 0.03 \mathrm{MPa} \sqrt{ } m$. The trend of the fracture toughness of the composite sample incorporating $10 \%$ by volume LDPE and $20 \%$ by volume calcium phosphate might be due to the presence of voids unfilled by LDPE particles and weak linkages due to matrix-matrix interactions of calcium phosphate particles. Due to the formation of weak interfaces within the particles, when cracks initiate they will propagate easily, without any serious impediment of LDPE and other particles in the microstructure.

The fracture modes obtained from optical images of the fracture surfaces using ProbScope for different formulations are shown in Figs. 5(a-d). The optical micrographs showed evidence of multiple cracking [Fig. 4(c)] and smooth transgranular cracking [Figs. 5(a-b)]. The Mode I (opening of cracks) type of fracture mode existed in these composites [Figs. 5(a-d)]. The quick setting and rapid hardening in the bricks was a result of recycling of polyethylene and phosphogypsum wastes, and this contributed to the overall toughening and strengthening mechanism in the bricks.
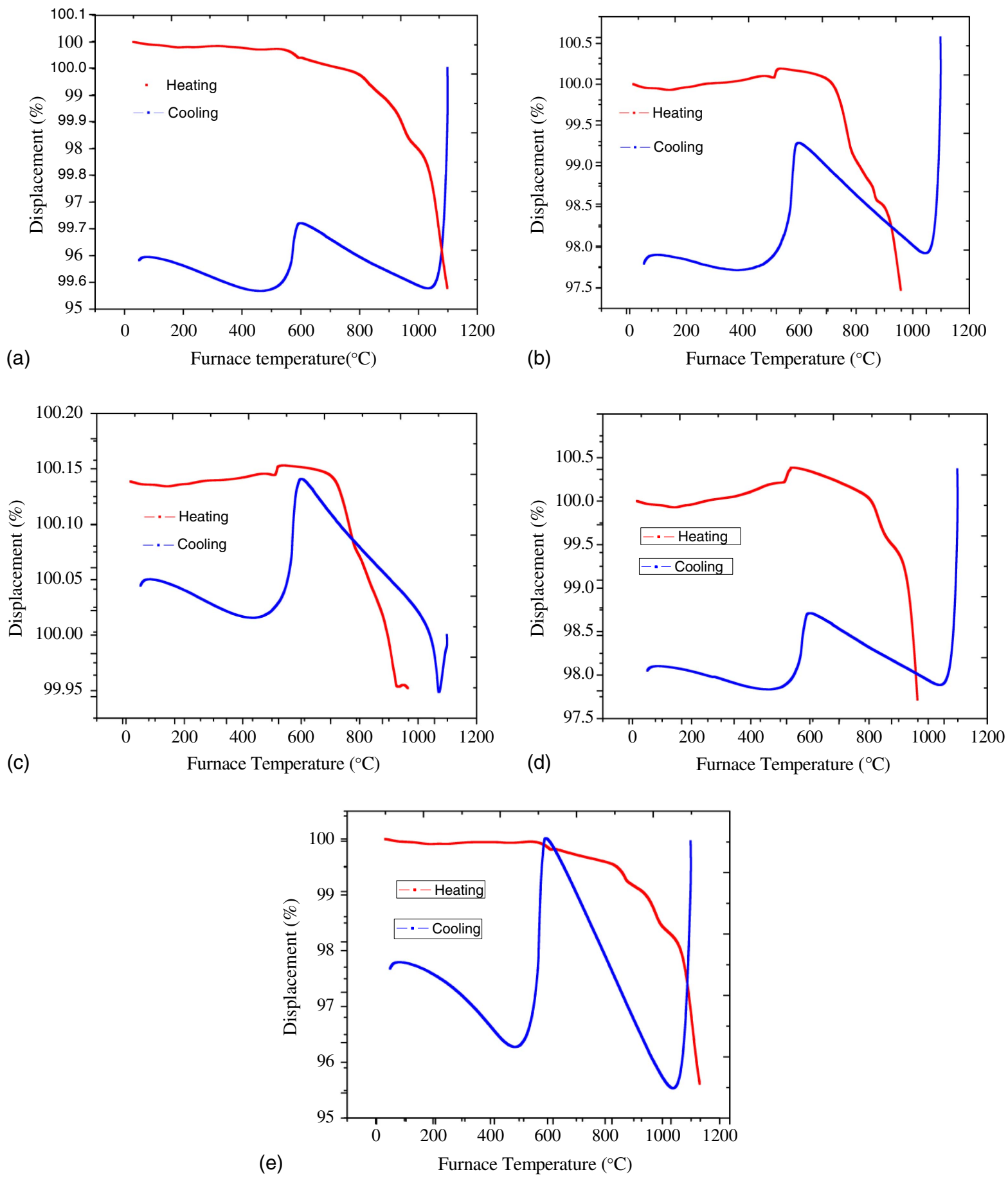

Fig. 12. TMA analysis of laterite with (a) $5 \%$ by volume biochar and $1 \%$ by volume LDPE; (b) $10 \%$ by volume biochar and $1 \%$ by volume LDPE; (c) $15 \%$ by volume biochar and $1 \%$ by volume LDPE; (d) gypsum; and (e) only laterite. 
The resistance curves obtained from the superposition of the toughening due to crack bridging on the initiation toughness are compared with the experimental resistance curves in Figs. 10(a-c). All the composites had initial toughness values of $\sim 0.4 \mathrm{MPa} \sqrt{m}$. Furthermore, the predictions of the SSB and LSB models exhibited similar characteristics [Figs. 10(a-c)]. The composite reinforced with $15 \%$ biochar [Fig. 10(c)] had the highest fracture toughness value, $\sim 1 \mathrm{MPa} \sqrt{m}$, whereas the composite sample formulated with $5 \%$ biochar had the lowest fracture toughness value, $\sim 0.56 \mathrm{MPa} \sqrt{m}$. This indicates improved fracture resistance of the formulated composite samples compared with that of the matrix of the composite. The increase in resistance to crack growth was found to be connected with microstructural interactions within the composites [Figs. 3(a) and 5(b)]. Crack bridging by low-density polyethylene and phosphogypsum particles played a vital role in the toughening of the overall composite, which is a significant scientific contribution to the web of knowledge.

\section{DSC/TGA}

The DSC/TGA results are illustrated in Figs. 11(a-e). All the composite compositions had similar exothermic crystallization temperatures, $\sim 300^{\circ} \mathrm{C}$. However, as expected, the total weight losses of the different composite compositions differed; the laterite material had a weight loss of $\sim 10.5 \%$ [Fig. 11(a)], whereas the laterite + biochar, laterite + LDPE + biochar, and laterite + phosphate + LDPE had weight losses of $\sim 13.1 \%, \sim 22.5 \%$, and $\sim 14.8 \%$, respectively. In addition, laterite mixed with gypsum had a weight loss of $\sim 14.6 \%$ [Fig. 9(e)]. The crystallization temperature (usually an exothermic reaction) of the different composites affected their mechanical properties.

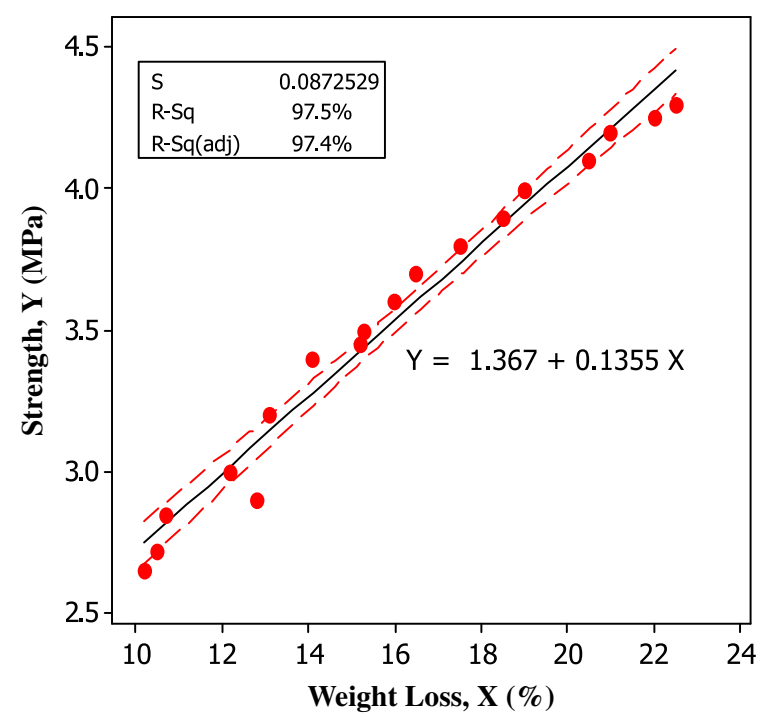

Fig. 13. Regression analysis of strength versus weight loss.

\section{ThermoMechanical Analysis Results}

The TMA analysis of the composites is presented in Figs. 12(a-e), which show the behavior of the different composites upon heating and cooling. Softening, cold crystallization, and particle shrinkage occurred during the heating curves. Particle shrinkage occurred due to increase in mobility of the molecules. The laterite material had a sintering temperature of $\sim 820^{\circ} \mathrm{C}$ after going through softening, cold crystallization, and cooling [Fig. 12(e)], whereas the lateriteLDPE composite mixed with $5 \%, 10 \%$, and $15 \%$ by weight biochar had sintering temperatures of $\sim 850^{\circ} \mathrm{C}, \sim 720^{\circ} \mathrm{C}$, and $\sim 710^{\circ} \mathrm{C}$, respectively [Figs. 12(a-c)]. A sintering temperature of $\sim 800^{\circ} \mathrm{C}$ was found [Fig. 12(d)] for the mixture of laterite and gypsum. The LDPE particles in the composite served as phase change materials, and the availability of biochar enabled easy absorption of thermal energy from the sun's rays.

\section{Mechanical Strength Analysis}

The regression model linking the mechanical strength to the weight loss of the composites is illustrated in Fig. 13. The model predicts a linear relationship between strength and weight loss of the resulting composites. The $R-$ squared adjusted value of nearly $98 \%$ indicates a strong correlation between the strength and weight loss of the composites. This indicates that the strength of the composite increases when more weight is lost. This was attributed to the fact that more weight reduction strengthens the bonds in the composite. The linear association between the strength and weight loss of the composite identified in this work is a major scientific contribution to the web of knowledge.

\section{Statistical Analysis of Cracks}

The statistical analysis result of composite cracks is shown in Table 3. This analysis was conducted at a $95 \%$ confidence interval (CI) using Student's $t$-test. Crack formations and extensions for the different brick composites all had $p$-values less than 0.05. This means that the null hypothesis is rejected and the test statistic is statistically significant for crack formation and extension.

\section{Scientific Contribution}

This work used potential environmental pollutants and waste materials, such as low-density polyethylene and phosphogypsum, in multifunctional earth-based bricks for applications in sustainable buildings. The waste low-density polyethylene that was recycled served as a toughening material for crack-tip shielding by crack bridging in the composite. The phosphogypsum waste in the composite allowed quick setting and rapid hardening of the bricks, thereby increasing the bond strengths and overall strength in the bricks. Furthermore, the linear association between the strength and weight loss of the low-density polyethylene composite is a major scientific contribution to the body of knowledge. Finally, the LDPE particles in the composites can serve as a phase change material, and the biochar absorbs heat from the sun's rays.

Table 3. Statistical analysis of cracks

\begin{tabular}{|c|c|c|c|c|c|c|c|}
\hline Variable & $N$ & Mean & Standard deviation & SE mean & $95 \% \mathrm{CI}$ & $T$ & $P$ \\
\hline Laterite only & 8 & 1.699 & 2.114 & 0.748 & $(-0.069,3.467)$ & -3.08 & 0.018 \\
\hline Laterite with PE and biochar & 8 & 1.087 & 1.290 & 0.456 & $(0.008,2.165)$ & -4.19 & 0.004 \\
\hline Laterite with gypsum & 8 & 1.051 & 1.247 & 0.441 & $(0.008,2.093)$ & -4.42 & 0.003 \\
\hline Laterite with $\mathrm{PE}, \mathrm{CaP}$, and gypsum & 8 & 0.391 & 0.384 & 0.136 & $(0.070,0.712)$ & -4.48 & 0.003 \\
\hline
\end{tabular}




\section{Implications}

This study showed that recycled LDPE particles containing calcium phosphate and phosphogypsum can be utilized as reinforcements in cement-stabilized laterite composites. The utilization of such reinforcement could help decrease the quantity of cement that is used in construction applications. In addition, phosphogypsum, an industrial by-product, can be beneficial to the construction industry, reducing the adverse effects of this pollutant on the environment.

The LDPE-laterite-phosphate-gypsum composites had excellent combinations of flexural strength, compressive strength and fracture toughness values (Table 1). Furthermore, the optimum balance of compressive strength, flexural strength and fracture toughness was observed in the LDPE-laterite-phosphate-gypsum composite reinforced with a combination of $20 \%$ by volume LDPE, $15 \%$ by volume gypsum, and $15 \%$ by volume calcium phosphate.

After sintering, the laterite composite reinforced with $1 \%$ by volume LDPE and $15 \%$ by volume biochar had the best combination of fracture toughness, $R$ curves, and thermal behavior. Therefore, reprocessed LDPE at volume fractions of $20 \%$ and the inclusion of $1 \%$ by volume LDPE and $15 \%$ by volume of biochar has the potential for application in construction materials, such as those that are used in sustainable housing and thermal energy storage.

\section{Conclusions}

The following conclusions can be made from this work:

1. Low-density polyethylene bags and gypsum waste can be reprocessed into laterite composite reinforcements for applications in the building and construction industry. The resulting LDPE-laterite-gypsum composite and laterite-LDPE-biochar composite each had excellent combinations of mechanical and thermal properties.

2. The composite reinforced with $1 \%$ by volume LDPE and $15 \%$ by volume biochar had the best combination of flexural strength, fracture toughness, and thermal behaviour after sintering at $850^{\circ} \mathrm{C}$, compared with those in other studies (Table 1). This composite has potential applications in infrastructural construction materials such as sustainable housing and thermal energy storage. The while biochar facilitates the absorption of thermal energy, and the LDPE helps bridge composite cracks; the also are phase change materials.

3. The introduction of the compound $\mathrm{AlSiO}_{2}(\mathrm{OH})_{2}$ in the kaolinite group partially was responsible for the overall strength in the composite due to its higher stacking regularity. The existence of $\mathrm{Mg}_{2.35} \mathrm{Fe}_{0.13} \mathrm{Al}_{0.52}$ provided quick setting and rapid hardening, leading to the overall strength of the composite, which is a key scientific contribution.

4. The statistical analysis showed that crack formation and extension of the different brick composites all had $p$-values less than 0.05. This means that the null hypothesis is rejected, and the test statistic is statistically significant for crack formations and extensions.

\section{Data Availability Statement}

Some or all data, models, or code that support the findings of this study are available from the corresponding author upon reasonable request.

\section{Acknowledgments}

The authors are grateful to Centre RAPSODEE, Ecole des Mines d'Albi, Albi, France and to Worcester Polytechnic Institute, Worcester, Massachusetts for their financial support.

\section{References}

Azeko, S. T., E. K. Arthur, Y. Danyuo, and M. Babagana. 2018. "Mechanical and physical properties of laterite bricks reinforced with reprocessed polyethylene waste for building applications." J. Mater. Civ. Eng. 30 (4): 04018039. https://doi.org/10.1061/(ASCE)MT.1943-5533 .0002205 .

Azeko, S. T., G. A. Etuk-Udo, O. S. Odusanya, K. Malatesta, N. Anuku, and W. O. Soboyejo. 2015a. "Biodegradation of linear low density polyethylene by Serratia marcescens subsp. marcescens and its cell free extracts." Waste Biomass Valorization 6 (6): 1047-1057. https://doi.org /10.1007/s12649-015-9421-0.

Azeko, S. T., K. Mustapha, E. Annan, O. S. Odusanya, and W. O. Soboyejo. 2015b. "Recycling of polyethylene into strong and tough earth-based composite building materials." J. Mater. Civ. Eng. 28 (2): 04015104. https://doi.org/10.1061/(ASCE)MT.1943-5533.0001385.

Azeko, S. T., K. Mustapha, E. Annan, O. S. Odusanya, A. B. O. Soboyejo, and W. O. Soboyejo. 2015c. "Statistical distributions of the strength and fracture toughness of recycled polyethylene-reinforced laterite composites." J. Mater. Civ. Eng. 28 (3): 04015146. https://doi.org/10 .1061/(ASCE)MT.1943-5533.0001426.

Benavente, V., and A. Fullana. 2015. "Torrefaction of olive mill waste." Biomass Bioenerg. 73 (Feb): 186-194. https://doi.org/10.1016/j .biombioe.2014.12.020.

Cha, J. S., S. H. Park, S.-C. Jung, C. Ryu, J.-K. Jeon, M.-C. Shin, and Y.-K. Park. 2016. "Production and utilization of biochar: A review." J. Ind. Eng. Chem. 40 (Aug): 1-15. https://doi.org/10.1016/j.jiec.2016.06.002.

Flomo, M. K., S. T. Azeko, E. K. Arthur, J. D. Kukurah, K. Mustapha, E. Annan, and B. Agyei-Tuffour. 2021. "Reinforcement of cement mortar with recycled polyethylene waste for construction applications." J. Compos. Mater. 00219983211000249.

Guo, X., R. Ji, G. J. Weng, L. L. Zhu, and J. Lu. 2014. "Micromechanical simulation of fracture behavior of nanostructured metals with bimodal grain size distribution." Procedia Mater. Sci. 3 (Jan): 2148-2153. https://doi.org/10.1016/j.mspro.2014.06.348.

Hanan, T., C. Mohammed, A. L. Felix, J. A. Francisco, and L-D. Aurora. 2009. "Environmental impact and management of phosphogypsum (review)." J. Environ. Manage. 90 (8): 2377-86.

Liu, Y. Y., M. F. McCabe, J. P. Evans, A. I. J. M. van Dijk, R. A. M. de Jeu, and H. Su. 2010. "Influence of cracking clays on satellite observed and model simulated soil moisture." Hydrol. Earth Syst. Sci. Discuss. 7: 907-927.

Macíasa, F., R. Pérez-Lópeza, C. R. Cánovasa, S. Carreroa, and P. CruzHernandeza. 2017. "Environmental assessment and management of Phosphogypsum according to European and United States of America regulations." Procedia Earth Planet. Sci. 17 (2017): 666-669.

Mahamat, A. A., I. I. Obianyo, B. Ngayakamo, N. L. Bih, O. Ayeni, S. T. Azeko, and H. Savastano, Jr. 2021. "Alkali activation of compacted termite mound soil for eco-friendly construction materials." Heliyon 7 (3): e06597. https://doi.org/10.1016/j.heliyon.2021.e06597.

Mustapha, K., E. Annan, S. T. Azeko, M. G. Zebaze Kana, and W. O. Soboyejo. 2016a. "Strength and fracture toughness of earth-based natural fiber-reinforced composites." J. Compos. Mater. 50 (9): 1145 1160. https://doi.org/10.1177/0021998315589769.

Mustapha, K., S. T. Azeko, E. Annan, M. G. Zebaze Kana, L. Daniel, and W. O. Soboyejo. 2016b. "Pull-out behavior of natural fiber from earthbased matrix." J. Compos. Mater. 50 (25): 3539-3550. https://doi.org /10.1177/0021998315622247.

Nunoura, T., S. R. Wade, J. P. Bourke, and M. J. Antal, Jr. 2006. "Studies of the flash carbonization process: Propagation of the flaming pyrolysis reaction and performance of a catalytic afterburner." Ind. Eng. Chem. Res. 45 (2): 585-599. https://doi.org/10.1021/ie050854y. 
Rashad, A. M. 2017. "Phosphogypsum as a construction material." J. Cleaner Prod. 166 (Nov): 732-743. https://doi.org/10.1016/j .jclepro.2017.08.049.

Savastano, H., Jr., P. G. Warden, and R. S. P. Coutts. 2000. "Brazilian waste fibres as reinforcement for cement-based composites." Cem. Concr. Compos. 22 (5): 379-384. https://doi.org/10.1016/S0958-9465(00) 00034-2.

Savastano, H., Jr., P. G. Warden, and R. S. P. Coutts. 2001. "Ground iron blast furnace slag as a matrix for cellulose-cement materials." Cem. Concr. Compos. 23 (4-5): 389-397.

Siddique, R. 2004. "Performance characteristics of high-volume Class F fly ash concrete." Cem. Concr. Res. 34 (3): 487-493. https://doi.org/10 .1016/j.cemconres.2003.09.002.
Srijaroen, C., M. Hoy, S. Horpibulsuk, R. Rachan, and A. Arulrajah. 2020. "Soil-cement screw pile: Alternative pile for low- and mediumrise buildings in soft Bangkok clay." J. Constr. Eng. Manage. 147 (2): 04020173. https://doi.org/10.1061/(ASCE)CO.1943-7862 0001988

Sukontasukkul, P., and C. Chaikaew. 2006. "Properties of concrete pedestrian block mixed with crumb rubber." Constr. Build. Mater. 20 (7): 450-457. https://doi.org/10.1016/j.conbuildmat.2005.01.040.

Weng, G. J. 2011. "A composite model of nanocrystalline materials." In Mechanical properties of nanocrystalline materials, 93-135.

Yang, X., et al. 2017. "Thermal properties of biochars derived from waste biomass generated by agricultural and forestry sectors." Energies 10 (4): 469. https://doi.org/10.3390/en10040469. 